\title{
A CENTRALIDADE DA FAMÍLIA NO PROCESSO DE DOAÇÃO DE ÓRGÃOS E TECIDOS
}

\author{
The central role of the family in the organ and tissue donation process
}

\author{
Cláudia Medrado Martins, Mayla Cosmo
}

\section{RESUMO}

Cresce a necessidade de órgãos para transplante, e o número de doações não atende à demanda, levando à morte muitos dos que aguardam na fila de espera. Objetivo: O objetivo deste estudo é aprofundar o conhecimento do processo de doação de órgãos e tecidos e discutir o papel da família, responsável por consentir ou não a doação. Métodos: Realizou-se revisão da literatura nas bases de dados MedLine e Scielo. Também foram analisados livros e artigos que se encontravam nas referências bibliográficas das fontes indexadas. Recorreu-se às palavras-chaves death brain, family and organ donation. Discussão: A abordagem de familiares para solicitação da doação é o ponto central em todo caminho que se percorre desde a constatação da morte encefálica do paciente até o consentimento ou não para doação. Percebe-se que a disseminação da informação é preponderante, mas não é apenas a falta de informação que interfere nos baixos índices de doação de órgãos e tecidos. Há diversos fatores psíquicos e sociais que merecem atenção, para que o desenvolvimento de estratégias de incentivo à doação de órgãos torne-se mais eficaz na nossa sociedade. O cuidado com a família é importante, suas ansiedades e fantasias podem reverter-se em desconfiança em relação à equipe de saúde. A manifestação em vida a favor ou contra a doação é relevante, por facilitar a tomada de decisão da família. Conclusão: A dificuldade de lidar com o tema morte perpassa todo esse processo, uma vez que a família se vê diante de uma situação inesperada e tem que lidar com o imponderável da finitude humana. Daí a importância do preparo técnico, ético e emocional da equipe de saúde que cuida do potencial doador, bem como da equipe responsável pela captação e abordagem à família. É essencial compreender e respeitar as condições emocionais em que a família se encontrar antes de apresentar a possibilidade da doação de órgãos.

Descritores: Morte Encefálica; Família; Doação de Órgão.

\section{Instituições:}

Psicologia da Pontifícia Universidade Católica do Rio de Janeiro (Curso de Especialização em Psicologia da Saúde)

Correspondência:

Cláudia Medrado Martins

Endereço: Rua Conde de Bonfim, 120/sl. 716, Tijuca, Rio de Janeiro - RJ -CEP 20520-053

Tel: 21-2294-5982

E-mail: clamedmar@gmail.com

Recebido em: 11.11 .2009

\section{INTRODUÇÃO}

A família está na centralidade do processo de doação pós mortem; assim, faz-se necessário refletir sobre alguns pontos dolorosos nesse processo de antecipação de perdas futuras, de ameaça com o surgimento da doença aguda e a notícia da morte da pessoa querida, seguido do pedido de doação de órgãos e tecidos para fins de transplante.

A doação de órgãos é um tema de grande relevância, uma vez que cresce a necessidade de órgãos para transplante e o número de doações não atende a demanda, levando à morte muitos dos que aguardam na fila de espera. Por força da lei, qualquer doação de órgãos dependerá do consentimento familiar, trazendo para o centro desse processo a família, que é solicitada a se posicionar no exato momento em que se encontra em choque e em sofrimento diante da perda. Toda essa circunstância pode levar a uma dificuldade para refletir com clareza sobre o diagnóstico de morte encefálica, apontando para aspectos emocionais que envolvem a situação da perda.

\section{MÉTODO}

$\mathrm{Na}$ presente revisão da literatura, recorreu-se às bases de dados MedLine e Scielo e à análise de livros e dissertações encontrados nas referências bibliográficas de fontes indexadas. Combinaram-se 
os descritores morte encefálica, família e doação de órgãos e tecidos. O período consultado compreendeu 1997 - 2009, e foi localizado inicialmente um total de 372 referências. Na base de dados Scielo, foram encontradas 34 referências, sendo a primeira referência datada de 1998. Desses artigos, foram excluídos aqueles escritos em outras línguas que não a portuguesa e artigos não disponíveis em texto completo para download na Internet. O objetivo deste estudo é aprofundar o conhecimento do processo de doação de órgãos e discutir o papel da família neste contexto.

$\mathrm{O}$ artigo foi subdividido em 3 temas, que serão abordados a seguir: 'morte encefálica e família'; 'o processo de doação de órgãos e tecidos' e 'a entrevista familiar'.

\section{Morte encefálica e família}

A morte repentina, como conseqüência de agravos cerebrais severos e agudos, é precursora da doação de múltiplos órgãos, sendo a morte encefálica - que compreende a morte do cérebro, incluindo tronco cerebral - condição primordial para que aconteça a doação. É fundamental que os órgãos sejam aproveitados para doação enquanto ainda há circulação sangüínea irrigando-os, isto é, antes que o coração deixe de bater e os aparelhos não possam mais manter a respiração do paciente..$^{1-4}$

Entretanto, o tema não pode ser apreciado apenas pelo prisma da lei, já que na cultura brasileira, a morte é vista com resistência e, no que tange à morte encefálica, ela é agressiva, imprevista, traz angústia e desolação. As famílias, ao receberem tal diagnóstico, vivenciam uma experiência de choque, desespero e negação, e se mostram muitas vezes incapazes de compreender e aceitar essa realidade, podendo, inclusive, questionar a veracidade dos exames.5

A dificuldade de compreensão do conceito de morte encefálica dificulta a tomada de decisão quanto à doação de órgãos, pois autorizar a doação é uma situação difícil e complexa. Presenciar aquele que lhe é tão caro com todo suporte terapêutico que mantém o organismo funcionando e autorizar a doação nessa condição desperta a sensação de estar autorizando a morte do ente querido. 6

A morte encefálica, em sua maioria, é decorrente de acidente vascular encefálico ou de causas externas, tais como violência urbana, acidentes automobilísticos, atropelamentos e quedas. Esse cenário revela potenciais doadores internados nos Centros de Terapia Intensiva. Em uma pesquisa realizada com 10 famílias sobre as repercussões emocionais da morte encefálica, COSMO e KITAJIMA (2008) apresentam como causas dessa evolução, as seguintes doenças: $50 \%$ AVC, $25 \%$ traumatismo crânio encefálico, $12,5 \%$ pós-operatório ressecção aneurisma* e 12,5\% síndrome da imunodeficiência adquirida. ${ }^{5}$

Nesses casos, as internações dão-se de forma inesperada, envolvendo diversos aspectos. A pessoa apresentava-se bem saudável antes do acidente ou do mal súbito e a ocorrência do evento de forma tão repentina é motivo de choque para a família. Quando esta recebe o diagnóstico de morte encefálica de um parente que se encontrava saudável, precisa lidar não apenas com a perda repentina, mas também com o processo que se abre quando lhe é pedida a doação de órgãos e tecidos para transplante. ${ }^{7}$

Nesse processo de vida/morte iminente, a família pode fazer uso do mecanismo de defesa de negação, reação típica expressa quando se toma conhecimento de que uma doença é fatal ou ameaça a vida de uma pessoa importante. A dificuldade da família em aceitar a condição de morte alimenta a esperança na recuperação. Assim, o familiar que crê na reversão do quadro clínico do paciente nega-se a conversar sobre a doação de órgãos, pois falar sobre o assunto é adicionar mais dor e sofrimento a quem está sofrendo com a situação de perda. ${ }^{8}$

É nesse momento que a equipe de captação de órgãos, após avaliar o potencial doador, aborda a família. O cenário dessa abordagem é o CTI ou uma unidade que disponha de equipamento de ventilação mecânica. Segundo MATTA (2006), surge “(...) o primeiro - e talvez mais fundamental - obstáculo que a equipe encontra: o entendimento, por parte da família, da morte encefálica". E prossegue:

"A concepção de morte presente em nossa cultura é a parada cardiorespiratória. É muito dificil a compreensão de que a morte do encéfalo determina a falência de todos os sistemas vitais e que naquele corpo não existe mais vida. Este fato, aliado à mobilização de mecanismos de defesa, como a negação e a racionalização, torna o momento da abordagem da familia o mais difícil e delicado de todo o processo de captação e transplante" (p. 374 ). ${ }^{9}$

A morte encefálica encontra resistência não apenas na população em geral, mas também entre profissionais de saúde que assistem o potencial doador, representando um obstáculo na aceitação da doação de órgãos por parte das famílias. ${ }^{7,10}$ Esse aspecto deve ser considerado no momento de abrir o processo de doação de órgãos e tecidos para transplantes.

Neste contexto, a equipe de saúde e a família têm responsabilidades importantes no processo de doação de órgãos. Não se trata de uma determinação somente técnica: é um ato normativo, momento desencadeador de conflitos e decisões que põem em jogo a dinâmica familiar. Ao mesmo tempo em que a família perde uma pessoa querida, precisa decidir ou não pela doação de órgãos. ${ }^{9}$

\section{O processo de doação de órgãos e tecidos}

O cuidado com a família é importante, pois suas ansiedades e fantasias podem reverter-se em desconfiança em relação à equipe de saúde. Uma doença traz consigo potencial ameaça à continuidade da existência, e assim, carrega a presença da morte. Esse momento de tomada de decisão (consentir ou não a doação de órgão e tecidos daquele que acaba de falecer) traz a revelação da precariedade, transitoriedade e dos limites da existência. ${ }^{11}$

A família emerge como elemento central no processo de doação de órgãos e tecidos. De um ângulo, é percebida como principal obstáculo à efetivação dos transplantes, e, de outro, é sentida como vítima em todo o processo, adicionando-se à dor da perda brusca e traumática, o grande desgaste que representa a decisão de doar. ${ }^{12}$

A abordagem para solicitar a doação deve ser realizada quando os familiares oferecem condições emocionais e estão devidamente esclarecidos para decidir de forma consciente e com autonomia. Deve-se esclarecer as etapas da doação, os órgãos que são possíveis de serem doados e que a decisão pode ser revogada a qualquer tempo, mesmo depois de ter sido assinado o termo de consentimento. Explicar também alguns pontos como a mutilação e desfiguração do corpo, ausência de custo para a familia e os procedimentos referentes ao Instituto de Medicina Legal (IML), quando necessário, e atrasos no funeral. ${ }^{13}$ 


\section{A entrevista familiar}

A entrevista familiar é uma das etapas de maior complexidade em todo o processo, envolvendo aspectos éticos, legais e emocionais. A entrevista requer preparo por parte do profissional para elucidar dúvidas, compartilhar sentimentos e viabilizar o processo de doação. ${ }^{14}$

O pedido de doação vem junto com a comunicação da morte encefálica do familiar. Os parentes querem ter certeza do diagnóstico de morte, querem expressar suas dúvidas a respeito do que é a morte encefálica, de confiar ou não no diagnóstico, como funcionam os aparelhos, o que acontece após a doação ou quando não há doação. ${ }^{12}$ Surgem suposições referentes ao ato de desligar os aparelhos e a quem cabe tal responsabilidade.

A família precisa de tempo para manejar a dor pela perda sofrida, e a equipe de saúde, sem interferir nesses sentimentos, precisa ser sensível às solicitações e estar atenta ao processo de perda pelo qual a família está passando. ${ }^{15}$

Para prosseguir no processo, deve-se solicitar à família consentimento para remoção dos órgãos e tecidos, pois cabe a ela exclusivamente esse papel importante perante a legislação brasileira.

Surgem na cena diferentes sentimentos como desespero, tristeza profunda, revolta, choro compulsivo, crença que haverá reversão da situação e até mesmo aceitação da perda. Além disso, cada individuo/família se ampara em princípios, valores, crenças diversas que lhe são próprias e que influenciarão na decisão. ${ }^{16}$

Vários fatores podem motivar ou não as famílias a doar os órgãos de seus entes queridos, tais como: ${ }^{13}$

- Barreiras religiosas e culturais, pois são responsáveis por uma parcela das recusas em doar, a despeito de não haver objeções aos transplantes por parte da maioria das religiões;

- Desconhecimento dos desejos do familiar em morte encefálica sobre doação de órgãos;

- Questões emocionais que envolvem o momento da perda podem dificultar a reflexão clara, podendo levar a família a sentir-se sobrecarregada;

- Grau de satisfação com o atendimento hospitalar e com a relação estabelecida previamente com a equipe de saúde;

- Impressão do primeiro contato com os membros da Comissão Intra-Hospitalar de Doação de Órgãos e Tecidos (CIHDOTT), o momento em que a abordagem ocorre e os tópicos levantados durante a proposta de doação.

Este estudo aponta para o desempenho da instituição de saúde como fator que pode influenciar positiva ou negativamente o processo de doação de órgãos e tecidos. A instituição é depositária do bem valioso, e é a responsável pelo cuidado e por sua destinação. Assim, preconiza a importância do contato com os familiares durante o processo e após a retirada dos órgãos. ${ }^{16}$

Fatores culturais e religiosos são também relevantes nos momentos finais da vida humana. Um estudo ${ }^{12}$ sobre a percepção de famílias ao consentirem doar os órgãos do familiar que acaba de falecer aponta que:

- A doação pode ser uma escolha consciente, expressando a vontade da família. Geralmente, está associada a experiências positivas de doação por corresponder a um desejo genuíno da família em doar.
- A doação pode ser apenas como concordância, sem reflexão. Esta atitude associa-se a experiências familiares traumáticas de doação, avaliada pelos familiares como uma experiência negativa.

- Para as famílias da pesquisa, a doação de órgãos altera profundamente os hábitos e os rituais religiosos que celebram a despedida do ente querido.

- Para alguns familiares, depois de decorrido considerável período de tempo, ainda apresentavam conflitos na dinâmica familiar e relato de dificuldades de dormir por estarem preocupados com a possibilidade de terem causado algum dano ao doador, por não terem certeza da morte do doador; e vivências de conflitos entre alguns membros da família sobre a decisão de doar, gerando revolta e animosidade.

Os achados desse estudo chamam atenção para rituais, crenças e necessidades da família, que envolvem um tempo com aquele que acaba de falecer, um tempo de despedida, um tempo para os rituais religiosos e um espaço que propiciará aos familiares a via de aceitação emocional e social da perda da pessoa querida. Os avanços tecnológicos se apresentam interferindo nos hábitos culturais e religiosos presentes e importantes nas famílias. ${ }^{13}$

A doação de órgãos do familiar, mesmo quando o paciente tenha manifestado em vida seu desejo, deixa marcas. Tomar a decisão de autorizar a retirada de órgãos de outra pessoa que não pode mais decidir, remete a assumir a responsabilidade de um ato lesivo ao bem daquela pessoa (o próprio corpo), sem ter certeza de qual seria sua vontade naquela situação. ${ }^{16}$

\section{DISCUSSÃO}

A família exerce papel preponderante no processo de doação de órgãos e tecidos. A continência, apoio emocional, acolhimento e respaldo oferecidos pela equipe de saúde podem ser determinantes nesse processo, uma vez que durante a internação, a família é atingida por uma "desorganização de seu cotidiano", tendo em vista que a dinâmica familiar se caracteriza pela participação de todos os seus membros, cada um ocupando um lugar social e um lugar emocional. A ruptura em decorrência da hospitalização, por si só, afeta a engrenagem dessa dinâmica, conflitos podem ser ativados ou reavivados da mesma forma como certos vínculos são intensificados. ${ }^{11,16}$

Os familiares dos potenciais doadores relacionam um conjunto amplo de fatores que permeiam as situações entre apoiar ou não o processo de doação, tais como: crença religiosa; espera de um milagre; entendimento ou não do diagnóstico de morte encefálica e crença na reversibilidade do quadro clínico; a inadequação da informação e ausência de confirmação da morte encefálica; desconfiança na assistência; inadequação no processo de doação; desejo do falecido, expresso em vida, de ser ou não doador e medo da perda da pessoa querida. O não doar, por vezes, pode estar ligado ao desejo de preservar o falecido de mais traumas, no sentido de que a retirada de órgãos é vivenciada, algumas vezes, como prolongamento do sofrimento. ${ }^{13,16}$

Inúmeras são as emoções que podem ser elencadas nesse processo, mas o importante é respeitar as diferentes formas que as famílias possuem de superar situações e não há um modelo preestabelecido que represente a melhor forma de proceder. Por um ângulo, diversas vezes a idéia de unidade de família e identidade familiar se apresenta 
fortemente marcada por um sistema de trocas baseado no valor da família. Já por outro ângulo, nas unidades familiares urbanas contemporâneas, essa identidade já não é tão clara e expõe-se dispersa e conflituosa, principalmente quando ocorre a emergência de uma demanda complexa e completamente desconhecida para a maioria das famílias quanto a doação de órgãos. ${ }^{17}$

O ser humano sabe que é finito e tenta desesperadamente negar essa idéia, embora não faça mais que confirmá-la nas intermináveis tentativas de planejamento de sua vida. Não pensar, não conversar sobre a morte pode ser um mecanismo para diminuir o sofrimento. Mas, apesar das tentativas da sociedade em negar o morrer, todos vão vivenciá-la, direta ou indiretamente. ${ }^{18}$ A mobilização de mecanismos de defesa como negação e racionalização torna o momento da abordagem da família um dos mais difíceis de todo o processo de captação e transplante. ${ }^{8}$ Qualquer tipo de pressão ou precipitação sobre a tomada de decisão do familiar pode levar a desperdiçar todo um trabalho de esclarecimento e acolhimento oferecido pela CIHDOTT; contudo, a demora na decisão por parte da família pode comprometer a viabilidade dos órgãos para transplante. ${ }^{9}$

\section{CONCLUSÃO}

A família é um grupo social que deve ser respeitada em seu sofrimento. A equipe de saúde, ao convidar os membros da família a refletir sobre a doação de órgãos, deve acolhê-la com informações, transparência, dignidade e respeitar a decisão que cada família tomar.

Diante da situação de morte encefálica, os familiares se deparam com o questionamento sobre a possibilidade de autorizar ou não a doação de órgãos. É nesse momento que se projeta uma realidade na qual atuam os mecanismos de defesa, crenças religiosas e a bagagem da história cada um.

É importante destacar que os familiares devem sempre receber apoio e ser acompanhados durante todo o processo até a entrega do corpo à família, independente da concordância ou da não na doação de órgãos.

Sendo assim, o serviço de psicologia pode ajudar nesse processo de abordagem da família pela equipe de saúde, facilitando o manejo de possíveis dificuldades e mecanismos suscitados pela perda inesperada.

\section{ABSTRACT}

Since there is an increasing need for organ transplantation and the amount of donors does not meet the demand, this leads to death many of those who are waiting for an organ. Purpose: "To deepen the knowledge on the organ and tissue donation process, and to discuss the family's role and responsibility whether to consent or not. Methods: To make a review of the literature on the MedLine and Scielo databases. Books and articles listed as bibliographical references and resources in the indexed literature were analyzed. The words death brain, family and organ and tissue donation were matched. Discussion: To approach family members to request organ donation is the starting point to the donation process, that when the patient is deemed to be in brain death is often concluded with the family's decision whether to consent or not. The spreading of information is a predominant factor that leads to low levels of organ donation. However, there are psychological and social factors that deserve special attention, as they are critical to the development of strategies to encourage the effective organ donation in our society. To express the wish to donate or not while one is still alive eases the family's burden to make such a decision. Conclusion: Dealing with the issue of death through the entire process is a very hard situation, since the family is facing an unexpected death and it has to deal with the imponderable human finitude. This is the major reason for the importance of the technical, ethical and emotional ability of the health team taking care of potential donors together with those professionals responsible for seeking out and approaching the family is. It is essential to understand and respect several issues the family has to face, in order to successfully present the possibility to the organ donation.

Keywords: Brain Death, Family; Organ Donation

\section{REFERÊNCIAS}

1. Ministério da saúde-Sistema Nacional de Transplantes. Governo Federal. [homepage na Internet]. Brasília; 2008 [acesso em: 2008 set. 06]. Disponível em: http://portal. saude.gov.br/portal/saude/area.cfm?id_area $=1004$.

2. Associação Brasileira de Transplante de Órgãos (ABTO) [homepage na Internet] São Paulo; 2008. [acesso em 2008 set. 05]. Disponível em: http://www.abto.org. br/profissionais/profissionais.asp/.

3. Lamb D. Transplante de órgãos e ética. São Paulo: Sobravime/Editora Hucitec; 2000.

4. Lei 9.434. 04 fev. de 1997 - Dispõe sobre a remoção de órgãos, tecidos e partes do corpo humano, para fins de transplante, tratamento e dá outras providências. Diário Oficial da União, Brasília, Seção 1, p.2192. (05 fev,1997).

5. Cosmo M, Kitajima KB. À espera de um milagre: a família diante da morte encefálica In: XIII Congresso Brasileiro de Medicina Intensiva-Adulto-Pediátrico-Neonatal, 2008, Salvador. RBTI Suplemento 2008. São Paulo: AMIB, 2008. p. 78.
6. Moraes MW de, Gallani MCBJ, Meneghin P. Crenças que influenciam adolescentes na doação de órgãos. Rev. esc. enferm. USP [periódico na Internet]. 2006 Dez [acesso 2009 Abr 27] ; 40(4): 484-492. Disponível em: http://www.scielo.br/scielo. php?script $=$ sci_arttext\&pid=S0080-62342006000400006\&lng=pt. doi: 10.1590 / S0080-62342006000400006.

7. Moraes EL de, Massarollo MCKB. A recusa familiar para a doação de órgãos e tecidos para transplante. Rev Latino-Am Enfermagem. [periódico na Internet]. 2008 Jun [acesso em 2009 Mar 20] ; 16(3):458-64. Disponível em: http://www. scielo.br/scielo.php?script=sci_arttext\&pid=S0104-11692008000300020\&lng=pt. doi: 10.1590/S0104-11692008000300020.

8. Ismael SMC. A família do paciente em UTI. In: Mello Filho J, Burd M. Doença e família. São Paulo: Casa do Psicólogo. 2004. p. 251-57.

9. Matta GC. Família, práticas institucionais e transplantes de órgãos. In: Mello Filho J, Burd M. Doença e família. São Paulo: Casa do Psicólogo. 2004. p. 365-76. 
10. Bitencourt AGV, Neves FBCS, Durães L, Nascimento DT, Neves NMBC, Torreão LA et al . Avaliação do conhecimento de estudantes de medicina sobre morte encefálica. Rev. bras. ter. intensiva [periódico na Internet]. 2007 Jun [acesso 2009 Abr 28] ; 19(2): 144-150. Disponível em: http://www.scielo.br/scielo. php?script $=$ sci_arttext\&pid=S0103-507X2007000200002\&lng=pt. doi: 10.1590/ S0103-507X2007000200002.

11. Bousso RS. O processo de decisão familiar na doação de órgãos do filho: uma teoria substantiva. Texto contexto - enferm. [periódico na Internet]. 2008 Mar [acesso 2009 Abr 26] ; 17(1): 45-54. Disponível em: http://www.scielo.br/scielo. php?script=sci_arttext\&pid=S0104-07072008000100005\&lng=en. doi: 10.1590/ S0104-07072008000100005.

12. Sadala MLA. A experiência de doar na visão de familiares de doadores. J Bras Nefrolog. [periódico na Internet]. 2001 Mar [acesso em 2008 Nov 25]; 23(3):143-51. Disponível em: http://www.jbn.org.br/23-3/v23e3p143.pdf .

13. Rech TH, Rodrigues FEM. Entrevista familiar e consentimento. Rev bras ter. intensiva. [periódico na Internet]. 2007 Mar [acesso em 2008 Mar 18] ; 19(1): 85-9. Disponível em: http://www.scielo.br/scielo.php?script=sci_arttext\&pid=S0103507X2007000100011\&lng=pt. doi: 10.1590/S0103-507X2007000100011.
14. Guarino AJ. Stress e captação de órgãos: uma realidade vivenciada pelos enfermeiros [dissertação]. São Paulo: Escola de Enfermagem, Universidade de São Paulo; 2005.

15. Santos MJ dos, Massarollo MCKB. Processo de doação de órgãos: percepção de familiares de doadores cadáveres. Rev Latino-Am Enfermagem. [periódico na Internet]. 2005 Jun [acesso em 2008 Out 20]; 13(3): 382-7. Disponível em: http://www. scielo.br/scielo.php?script=sci_arttext\&pid=S0104-11692005000300013\&lng=pt. doi: 10.1590/S0104-11692005000300013.

16. Roza BA, Ferraz Neto B-H,Thomé T, Schirmer J. Doação de órgãos e tecidos no Brasil: podemos evoluir? O Mundo da Saúde São Paulo [periódico na Internet]. 2009 Jan [acesso em Jun 2009; 33(1):43-48. Disponível em: http://www.saocamilo-sp.br/ pdf/mundo_saude/66/43a48.pdf

17. Kaufmann ML. Um conflito onde doar não significa ganhar. Rev. bras. ter. intensiva [periódico na Internet]. 2001 Abr [acesso 2008 Mar 18] ; 13(2): 71-6. Disponível em: http://www.scielo.br/scielo.php?script=sci_arttext\&pid=S0103507X2006000300005\&lng=pt. doi: 10.1590/S0103-507X2006000300005.

18. Costa JF. O risco de cada um e outros ensaios de psicanálise e cultura. Rio de Janeiro: Garamond. 2007. 